\title{
Pitfalls during biomechanical testing - Evaluation of different fixation methods for measuring tendons endurance properties
}

\author{
Gy Hangody ${ }^{1}$, G Pánics ${ }^{1,3}$, G Szebényi², R Kiss ${ }^{2}$, L Hangody ${ }^{1,3}$, K Pap ${ }^{1,3}$ \\ ${ }^{1}$ Uzsoki Hospital Orthopedic-Traumatologic Department, Budapest, Hungary \\ ${ }^{2}$ Cooperation Research Center for Biomechanics, Budapest University of Technology and Economics, \\ Budapest, Hungary \\ ${ }^{3}$ Department of Traumatology, Semmelweis University, Budapest, Hungary
}

Received: April 18, 2015

Accepted: February 1, 2016

\begin{abstract}
The goal of the study was to find a proper technique to fix tendon grafts into an INSTRON loading machine. From 8 human cadavers, 40 grafts were collected. We removed the bone-patella tendon-bone grafts, the semitendinosus and gracilis tendons, the quadriceps tendon-bone grafts, the Achilles tendons, and the peroneus longus tendons from each lower extremity. We tested the tendon grafts with five different types of fixation devices: surgical thread (Premicron 3), general mounting clamp, wire mesh, cement fixation, and a modified clamp for an INSTRON loading machine. The mean failure load in case of surgical thread fixation was $(381 \mathrm{~N} \pm 26 \mathrm{~N})$. The results with the general clamp were $(527 \mathrm{~N} \pm 45 \mathrm{~N})$. The wire meshes were more promising $(750 \mathrm{~N} \pm 21 \mathrm{~N})$, but did not reach the outcomes we desired. Easy slippages of the ends of the tendons from the cement encasements were observed $(253 \mathrm{~N} \pm 18 \mathrm{~N})$. We then began to use Shi's clamp that could produce $977 \mathrm{~N} \pm 416 \mathrm{~N}$ peak force. We combined Shi's clamp with freezing of the graft and the rupture of the tendon itself demonstrated an average force of $2198 \mathrm{~N} \pm 773 \mathrm{~N}$. We determined that our modified frozen clamp fixed the specimens against high tensile forces.
\end{abstract}

Keywords: biomechanical testing, tendon allograft, frozen clamp, load to failure test, human tendons

ACL injuries have been treated with biological grafts (autografts or allografts). However, there are risks associated with the use of allografts, most notably being disease transmission - both bacterial and viral, such as human immunodeficiency virus (HIV) and hepatitis (9). To minimize the risk of disease transmission by allograft tissue, one of the most accepted procedures is the use of gamma irradiation. This method can damage the structure of the tendons and can decrease their biomechanical properties (6). We are planning to start biomechanical tests to compare endurance properties of human tendons after being sterilized with different doses. The first step of this project was to find a proper technique to fix the tendon grafts into an INSTRON loading machine.

The main problem with tendon clamps is that it is hard to maintain the high pressure, which is needed to provide enough friction force between the tendon and the clamp to resist a large tensile load, and at the same time to reduce the cutting effect of the clamp (7). The purpose of this paper was to introduce our attempts to find a proper fixation technique for allograft endurance tests, and adapt it to be compatible for our Instron loading machine.

Corresponding author: Károly Pap, MD, MSc, PhD

Department of Traumatology, Semmelweis University

Uzsoki u. 29-41, 1145-Budapest, Hungary

Phone: +36-70-4504903; E-mail:drpapster@gmail.com 


\section{Materials and Methods}

Forty grafts were collected from 8 human cadavers. We removed the bone-patella tendonbone grafts (BPTB grafts), the semitendinosus and gracilis tendons, the quadriceps tendonbone grafts, the Achilles tendons, and the peroneus longus tendons from each lower extremity. We tested 40 tendon grafts ( 5 from each cadaver) with six different types of fixation devices: surgical thread (Premicron 3), wire mesh, clamp, cement fixing, Shi's clamp (7) and Shi's modified, frozen clamp for an INSTRON loading machine.

Donor tissues were removed according to surgical protocols. The gracilis and the semitendinosus tendons were cut distally near to their tibial insertions and proximally at their muscle junction, using a stripper. The patellar tendons were harvested from the central portion of the tendon, 5 with and 5 without the tibial and patellar bone fragments. Similarly, the midportions of the quadriceps were also harvested. The mid-thirds of the Achilles tendons were removed, without the posterior half of the calcaneus. Incision was done below the lateral malleolus, and the peroneus longus tendon was identified. Stiches were inserted into the distal part, and then the tendon was removed with using a stripper. Both ends of each tendon were fixed with stiches. All soft tissue - including the paratenon - was removed from the tendons. Our grafts were $9-16 \mathrm{~mm}$ in width (Table I). All tendons were screened for degenerative changes visually and mechanically. There was no previous history evidence of injury or disease around these ligaments. To minimize the dehydration, specimens were put into physiological saline. The grafts were removed within 24 hours from death.

Table I. Data of the grafts

\begin{tabular}{|l|c|c|c|c|}
\hline & Length $(\mathbf{c m})$ & SD $(\mathbf{c m})$ & Width $(\mathbf{m m})$ & SD $(\mathbf{m m})$ \\
\hline Quadriceps & 9.25 & 1.6 & 16 & 1.6 \\
\hline Patella & 6.375 & 1.7 & 13 & 0.82 \\
\hline Semitendinisus & 10.375 & 0.48 & 9 & 0.82 \\
\hline Peroneus & 11.375 & 1.38 & 9.75 & 0.5 \\
\hline Achilles & 12.125 & 0.75 & 13.25 & 2.7 \\
\hline
\end{tabular}

An Instron 8872 universal servo hydraulic computer-controlled loading testing system was used for the endurance tests. The experimental velocity used in the machine was $20 \mathrm{~mm} /$ min. We experimented with six types of fixation techniques.

In the first case, the grafts were secured with Premicron 3 suture into the tendon fibers, which was the theoretical basis for the hamstring ACL reconstruction technique (Fig. 1). The second option was a fixation encased in cement (Fig. 2). Both free ends of the specimens was covered with bi-componential bone cement, and secured between the jaws of clamp. We then used the available and already established mounting clamp (Fig. 3). The fourth type of fixation was a wire mesh, which only could be used for the fixation of bony blocks (Fig. 4). When the loading machine started to pull the mesh, it expanded the mesh and decreased its diameter. This tightening of the mesh secures the bony ends. We could not find a smaller diameter wire mesh that could secure the tendon ends which were thinner than the bony ends; this why only BPTB grafts were tested in that way. In the fifth type of fixation method, we used Shi's clamp (7) and we developed a special device to fix it into the INSTRON loading 
machine (Fig. 5). Lastly, we created two pockets for both sides of each clamp, with the help of dry-ice and we froze these clamps for a better fixation (Fig. 6). The data was evaluated by unpaired T-tests.
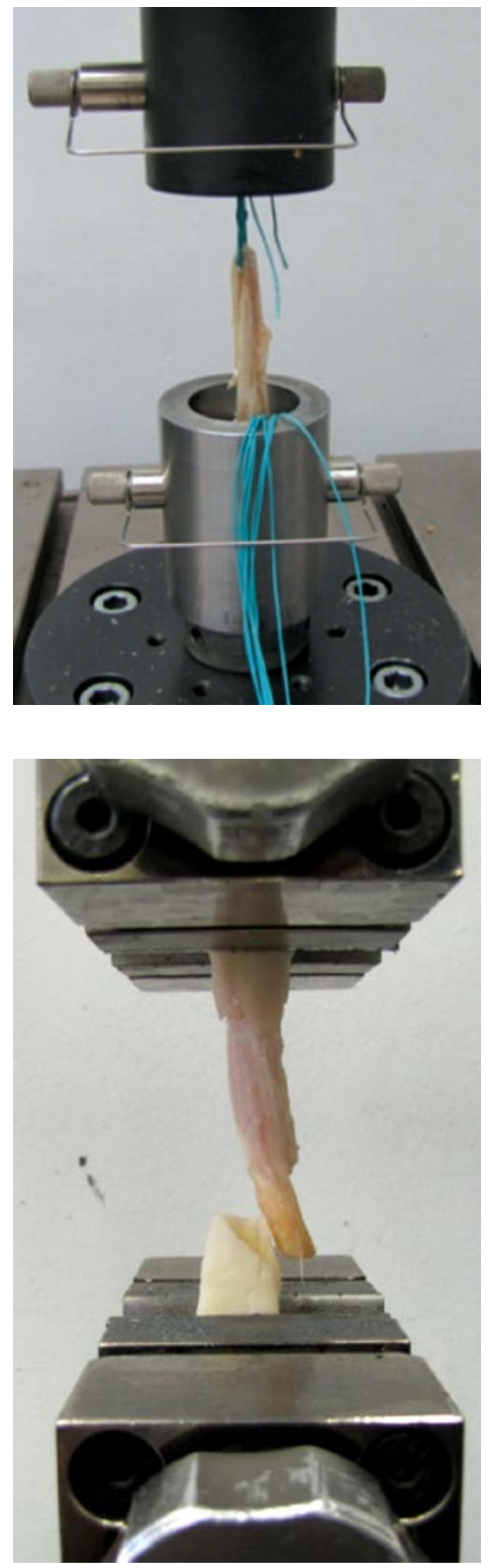

Fig. 1. The semitendinosus tendon sutured via Premicron 3 recording by the Instron loading machine

Fig. 2. Sliding out of Achilles graft from the cement mantle 

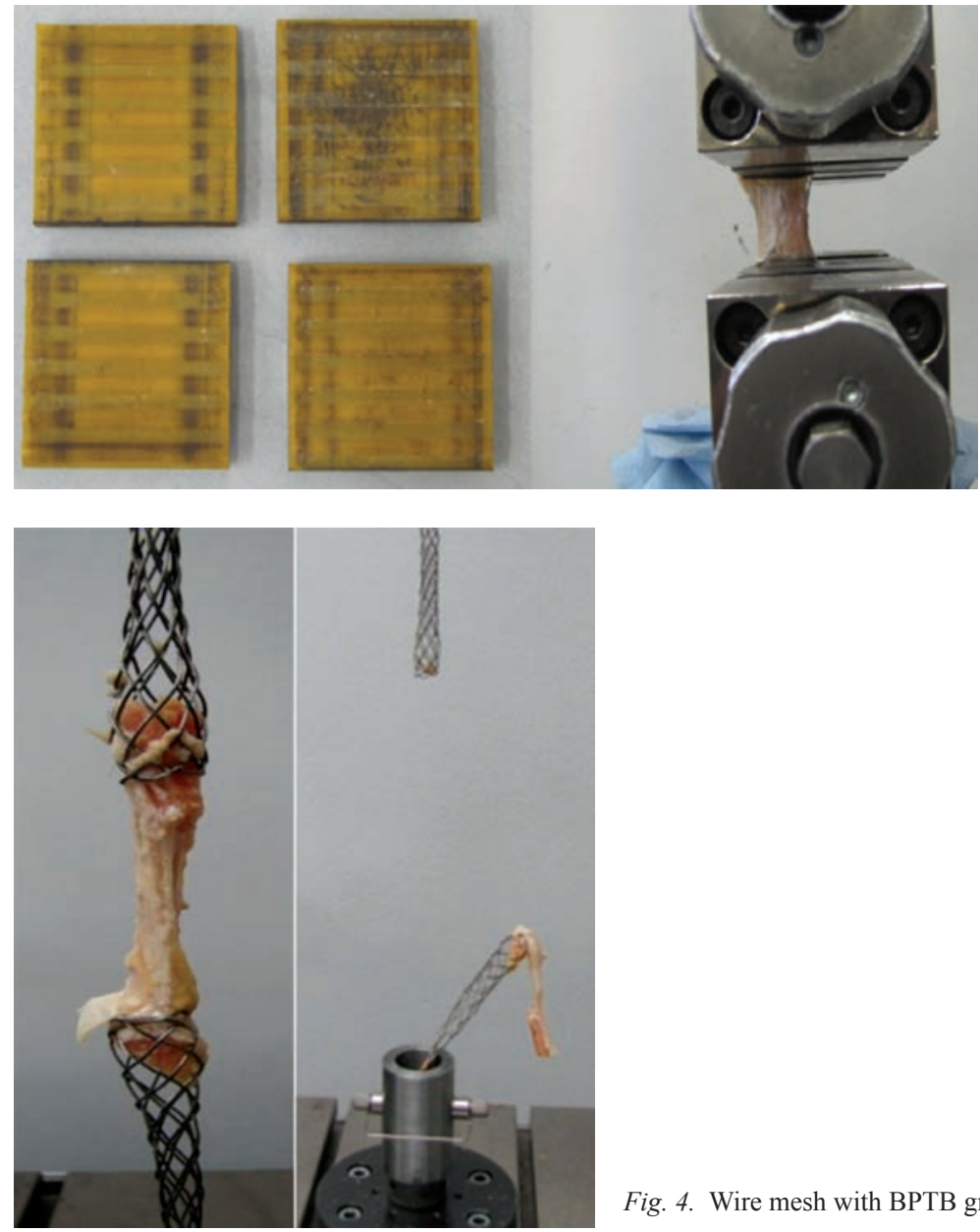

Fig. 4. Wire mesh with BPTB graft
Fig. 3. Tensile test with our ordinary mounting clamp

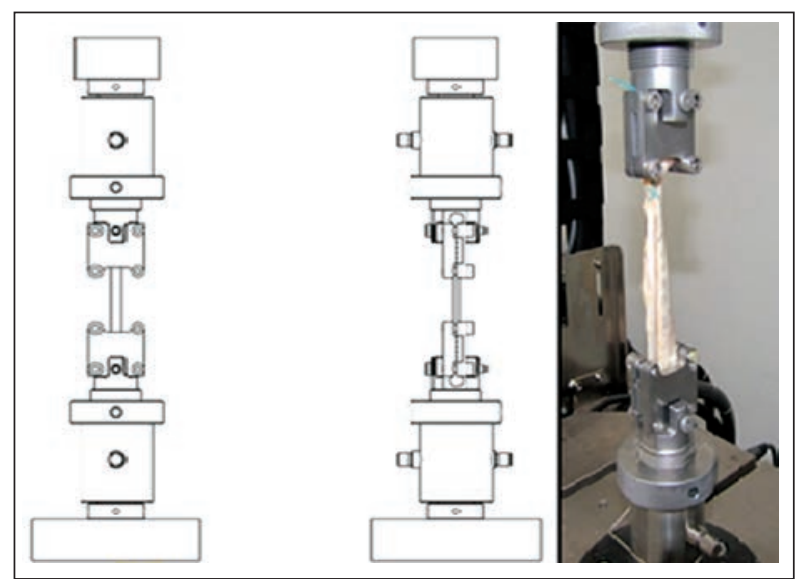

Fig. 5. Shi's modified clamp 


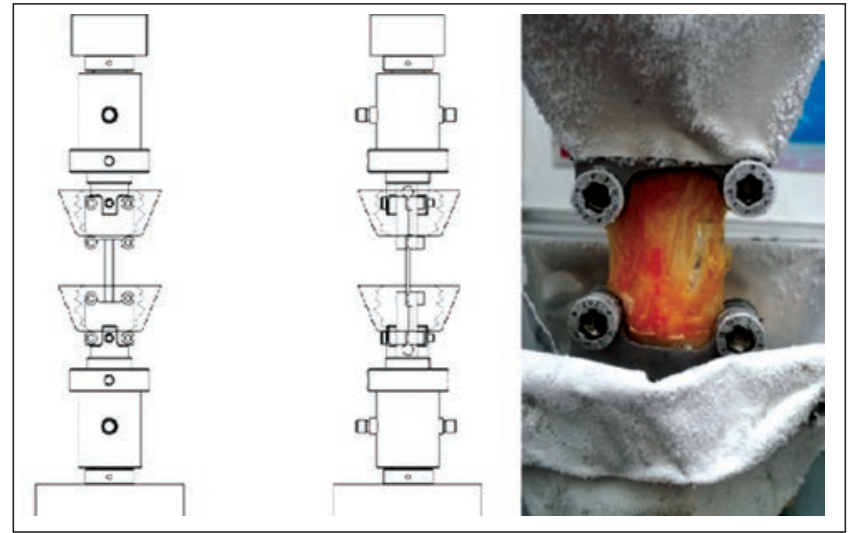

Fig. 6. Shi's modified and frozen clamp

\section{Results}

Fixation of the grafts were achieved as done in anterior cruciate ligament reconstructions, by suturing the free ends of the quadrupled (double-folded) semitendinosus and gracilis tendons or likewise the peroneus longus tendons using Premicron 3 sutures. The mean failure loads ranged from $362 \pm 24$ to $436 \pm 52 \mathrm{~N}$ according to Sakaguchi et al. (1, 5), which corresponded to the values of $381 \mathrm{~N} \pm 26 \mathrm{~N}$ we measured in our study (Table II, Fig. 7).

Table II. Values of tensile forces measured during the implementation of the six types of fixation methods, measured in Newton

\begin{tabular}{|l|c|c|c|c|c|c|}
\hline Graft & $\begin{array}{c}\text { Premicron 3 } \\
\text { thread }\end{array}$ & $\begin{array}{c}\text { Cemented } \\
\text { fixation }\end{array}$ & $\begin{array}{c}\text { Conventional } \\
\text { clamp }\end{array}$ & Wire mesh & $\begin{array}{c}\text { Shi's modified } \\
\text { clamp }\end{array}$ & $\begin{array}{c}\text { Shi's frozen } \\
\text { clamp }\end{array}$ \\
\hline Patella & $380 \mathrm{~N}$ & $250 \mathrm{~N}$ & $549 \mathrm{~N}$ & $745 \mathrm{~N}$ & - & - \\
\hline Peroneus & $402 \mathrm{~N}$ & $268 \mathrm{~N}$ & $483 \mathrm{~N}$ & $769 \mathrm{~N}$ & 1189 & $1791.5 \mathrm{~N}$ \\
\hline Quadriceps & $361 \mathrm{~N}$ & $275 \mathrm{~N}$ & $557 \mathrm{~N}$ & $724 \mathrm{~N}$ & 592 & $1841 \mathrm{~N}$ \\
\hline SemiT & $412 \mathrm{~N}$ & $231 \mathrm{~N}$ & $572 \mathrm{~N}$ & $739 \mathrm{~N}$ & 677 & $1862 \mathrm{~N}$ \\
\hline Achilles & $350 \mathrm{~N}$ & $240 \mathrm{~N}$ & $473 \mathrm{~N}$ & $775 \mathrm{~N}$ & 1451 & $3298.5 \mathrm{~N}$ \\
\hline average & $381 \mathrm{~N}$ & $253 \mathrm{~N}$ & $527 \mathrm{~N}$ & $750 \mathrm{~N}$ & $977.25 \mathrm{~N} *$ & $2198.25 \mathrm{~N}$ \\
\hline SD & $26 \mathrm{~N}$ & $18 \mathrm{~N}$ & $45 \mathrm{~N}$ & $21 \mathrm{~N}$ & $416 \mathrm{~N}$ & $773 \mathrm{~N}$ \\
\hline
\end{tabular}

* The difference was significant $\mathrm{p}>0.01$
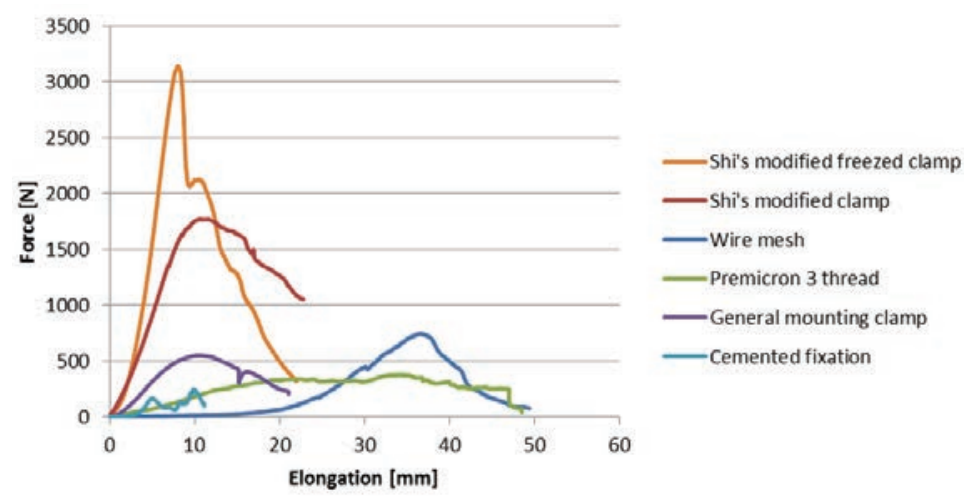

Fig. 7. Characteristic tensile curves of the different fixation devices 
In the second case, we tried to cement the ends of the grafts. Unfortunately, as it turned out, this was a complete failure $(253 \mathrm{~N} \pm 18 \mathrm{~N})$ (Table II, Fig. 7$)$, because of the very low friction coefficient between the tendon fibers and the cement, resulting in the relatively easy slippage of the ends of the tendons from the cement encasement. Unfortunately, in several cases, the cement mantle was damaged during the fixation into the clamp. We then tried to use the general mounting clamp. We did not achieve sufficient results here either $(527 \mathrm{~N} \pm$ $45 \mathrm{~N}$ ) (Table II, Fig. 2), since the tendons slipped out of the mounting clamp. In addition, the machines were unable to fasten the bony ends of the BPTB-grafts, because it would have resulted in severe damage of the polyethylene inlay of the clamp. In the fourth phase of our experiment, we tried a wire mesh fixation method. This could only be used for the fixation of the bony blocks of the BPTB grafts. The results were more promising $(750 \mathrm{~N} \pm 21 \mathrm{~N})$, but did not reach the outcomes we desired and this method was compatible with only one type of graft, therefore further improvements were needed (Table II, Fig. 2). Then we used Shi's clamp (7). Our objective was to find an ideal fixation method of the grafts, which can be applied to the universal fatigue testing machine, in order to continue further experimentation. The results were controversial. In cases of wider grafts - such as Achilles and quadriceps we measured higher friction forces, but thinner grafts - such as peroneus, semitendinosus slipped out in every case. The average loads to failure force were $997 \mathrm{~N} \pm 416$ (Table II, Fig. 7).

Lastly, we combined Shi's clamp with a freezing technique. The tensile load required $(2198 \mathrm{~N} \pm 773 \mathrm{~N})$ and the rupture of the tendon itself demonstrated that we found the mounting device needed for the strength testing of tendons (Table II, Fig. 7). The peak force was 3298.5 $\mathrm{N}$. We compared the results of the fifth and sixth fixation techniques. T-testing was performed and we found statistically significant differences between the two groups $(p<0.01)$. All grafts were torn (Fig. 7) except the patellar graft, where we were only able to reach a peak force of $1030 \mathrm{~N}$ in this type of graft. All of patellar grafts slid out from both Shi's clamp and from the frozen Shi's clamp. These grafts were only $6.375 \mathrm{~cm}$ long. The other grafts' average lengths were 9.25-12 cm (Table I).

\section{Discussion}

The major disadvantages of ACL reconstruction using an autologous technique include donor site morbidity, weakening of the flexor or extensor apparatus, and differences in graft sizes. In addition, more difficulties arise if a revision operation is necessary - due to a septic complication or re-rupture - or in the case of multiple knee ligament lesions; if we try to reconstruct the missing ligaments with the patient's own, there may not be enough implantable grafts, or only at the cost of significant morbidity to the donor site. For this reason, besides the most prevailing autologous technique, the use of allografts for ACL reconstruction in the past 10 years has increased, due to their many advantageous properties $(2,8)$. The biggest problem is that these are a "foreign tissue", therefore autoimmune reactions can occur (risking rejection), and they can transmit diseases. The other major problems are graft harvesting and storage. Keeping this in mind, we can state that a goal would be to create an "off the shelf" product, which can be pretreated with radiation and an anti-freeze solution, then sterilized with gamma rays (to be tested in the future). The first step in this process was the development of a mounting clamp for the forthcoming biomechanical tests.

In our study, we tested six different types of tendon graft fixation techniques. Shi's modified, frozen clamp was the only equipment that resulted proper, stable fixation during our endurance tests. Previously, it had been reported that embedding the bony ends of 
specimens into polymethymethaceylate (PMMA) were reliable for endurance tests (4). In case of hybrid tendons (such as Achilles tendon - where one end contains a bony fragment while the other is soft tissue) the soft tissue ends were gripped in nitrogen-oxide frozen clamp. Preparation of these fixation devices took too much time and needed too many materials if we want to test a large series of tendons. In our case, after the learning curve period, the insertion of the specimens into the clamp and the freezing took no longer than 8 minutes.

Great care had to be taken on the temperature of the frozen clamp. Tissues might have become frozen distal to the clamp, which may cause a decrease in the stress concentration leading to an unexpected rupture. It was reported that the average cooling time was 3-5 minutes (3). We used maximum 3 minutes of freezing time. We found no freezing signs - we did not find icing in the grafts near the clamps, and the saline on the surface of the tendons was liquid - in the graft tissues.

The thermoelectrically cooled tissue clamp (5) is also another possible device, which can be used for tendon biomechanical testing. In this case, the low temperature was reached by electricity. First, the cooling period lasts until the specimens reach a temperature of $0^{\circ} \mathrm{C}$, which is followed by a slow freezing period. The total preparation time was 45-85 minutes. This could be a problem when a researcher wants to test a large series of grafts.

The achievable tension of other clamps - mentioned in literature - ranged from $1300 \mathrm{~N}$ $\pm 229 \mathrm{~N}$ to $2549 \mathrm{~N} \pm 434 \mathrm{~N}(6)$. In our tests, we reached an average of $2198 \mathrm{~N} \pm 771 \mathrm{~N}$ tensile force and the peak force was $3298.5 \mathrm{~N}$, which corresponds to the previous data. In contrast to other studies, where the intact tendons were tested (4), we used only the mid-third of the Achilles, quadriceps, and patella tendons. Hoburg tested the mid-part of patellar tendons and measured $1630.5 \mathrm{~N} \pm 331.1 \mathrm{~N}$ (8), which gave similar results. In our study, we preferred to focus on the same sized grafts which we would use during anterior cruciate ligament reconstructions.

There are some disadvantages of Shi's modified clamp. They originally used cattle tendons that were similar in size of entire human Achilles tendons. The sizes of the grafts were 2-3 times wider then our specimens. The larger width means there is a larger connecting surface area, which results in higher bonding friction forces. We tested the appropriate size of the human tendons that we usually use for anterior cruciate reconstructions. This is the reason why in our study the thinner tendons slipped out. Another problem is that the fixation depends on the length of the grafts. We found that the specimens had to be at least $80 \mathrm{~mm}$ long or otherwise the grafts slide out. The reason is the same as mentioned above. The length of the polyethylene jaw of each clamp is $37 \mathrm{~mm}$. When doubled, it results $74 \mathrm{~mm}$, and we have to take into account the inter-clamp distance, which is about $5 \mathrm{~mm}$. If the tendons do not reach a length of $80 \mathrm{~mm}$, the connecting surfaces will not be large enough, resulting in decreased frictional forces, leading to slippage of the tendon from the clamp rather than rupture. Last of all, the disadvantage of the Shi's modified clamp is that it is not able to fix tendons with bony ends, because they damage the polyethylene insert.

In conclusion, we can say that our modified clamp worked well. It fixed the specimens against high tensile forces. As demonstrated in Fig. 7, only in the cases of the fifth and sixth fixation methods was a characteristic curve observed, which was similar to the load to failure curves. In case of the frozen clamp, the loading effect of the Instron loading machine was - significantly - more effective due to the better fixation. All other fixation method curves were rather characteristic for elastic elongation or slippage. 


\section{Acknowledgement}

This work was supported by the Hungarian Scientific Research Found (OTKA 1010170 grant).

\section{REFERENCES}

1. Bach BR, Aadalen KJ, Dennis MG, Carreira DS, Bojchuk J, Hayden JK, Bush-Joseph CA: Primary anterior cruciate ligament reconstruction using fresh-frozen, non-irradiated patellar allograft: minimum 2-year follow up. Am. J. Sports Med. 33, 284-292 (2005)

2. Hoburg AT, Keshlaf S, Schmidt T, Smith M, Gohs U, Perka C, Pruss A, Scheffler S: Effect of electron beam irradiation on biomechanical properties of patellar tendon allografts in anterior cruciate ligament reconstruction. Am. J. Sports Med. 38, 1134-1140 (2010)

3. Kiss MO, Hagemaister N, Levasseur A, Fernandes J, Lussier B, Petit Y: A low-cost thermoelectrically cooled tissue clamp for in vitro cyclic loading and load-to-failure testing of muscles and tendons. Med. Eng. Phys. 31, 1182-1186 (2009)

4. Pearsall AW, Hollis M, Russel GV, Scheer Z: A biomechanical comparison the three lower extremity tendons for ligamentous reconstruction about knee. Arthroscopy 19, 1091-1096 (2003)

5. Sakaguchi K, Tachibana Y, Oda H: Biomechanical properties of porcine flexor tendon fixation with varying throws and stich methods. Am. J. Sports Med. 40, 1641-1645 (2012)

6. Scheffler SU, Scherler J, Pruss A, von Versen R, Weiler A: Biomechanical comparison of human bone-patellar tendon-bone grafts after sterilization with peracetic acid ethanol. Cell Tissue Bank 6, 109-115 (2005)

7. Shi D, Wang D, Wang C, Liu A: A novel, inexpensive and easy to use tendon clamp for in vitro biomechanical testing. Med. Eng. Phys. 34, 516-520 (2012)

8. Wren TA, Yerby SA, Beaupré GS, Carter DR: Mechanical properties of the Achilles tendon. Clin. Biomech. 16, 245-251 (2001)

9. Yanke AB, Bell R, Lee A, Kang RW, Mather RC, Shewman EF, Wang VM, Bach BR Jr: The biomechanical effects of 1.0 to $1.2 \mathrm{Mrad}$ of gamma irradiation on human bone-patellar tendon-bone allografts. Am. J. Sports Med. 41, 835-840 (2013) 